\title{
Multivessel revascularisation versus infarct-related artery only revascularisation during the index primary PCI in STEMI patients with multivessel disease: a meta-analysis
}

\author{
S. Rasoul $\cdot$ V. van Ommen $\cdot$ J. Vainer $\cdot$ M. Ilhan $\cdot$ L. Veenstra $\cdot$ \\ R. Erdem - L.A.W. Ruiters • R. Theunissen - J.C.A. Hoorntje
}

Published online: 13 March 2015

(C) The Author(s) 2015. This article is published with open access at Springerlink.com

\begin{abstract}
Background There are controversial data regarding infarctrelated artery only (IRA-PCI) revascularisation versus multivessel revascularisation (MV-PCI) in ST-elevation myocardial infarction (STEMI) patients with multivessel disease undergoing primary percutaneous coronary intervention (PCI). We performed a meta-analysis comparing outcome in same stage MV-PCI versus IRA-PCI in STEMI patients with multivessel disease.

Methods Systematic searches of studies comparing MVPCI with IRA-PCI in the MEDLINE and the Cochrane Database of systematic reviews were conducted. A metaanalysis was performed of all available studies. Primary outcome was all-cause mortality. Secondary endpoints were re-infarction, revascularisation, bleeding and major adverse cardiac events (MACE).

Results A total of 15 studies were identified with a total number of 35,975 patients. Mortality rate was significantly higher in the MV-PCI group compared with the IRA-PCI group, odds ratio (OR): 1.64 (1.46-1.85). Both the incidence of re-infarction and re-PCI were significantly lower in the MV-PCI group compared with the IRA-PCI group: OR 0.54 (0.34-0.88) and OR 0.67 (0.48-0.93), respectively. Bleeding complications occurred more often in the MV-PCI group as compared with the IRA-PCI group: OR 1.24 (1.08-1.42). Rates of MACE were comparable between the two groups.
\end{abstract}

S. Rasoul $(\varangle) \cdot$ V. van Ommen · J. Vainer · M. Ilhan

L. Veenstra $\cdot$ L.A.W. Ruiters $\cdot$ R. Theunissen $\cdot$ J.C.A. Hoorntje Department of Cardiology, Maastricht University Medical Centre, PO Box 5800, 6202 AZ Maastricht, The Netherlands

e-mail: saman.rasoul@mumc.nl

J.C.A. Hoorntje $\cdot$ R. Erdem $\cdot$ S. Rasoul

Atrium Medisch Centrum Heerlen,

Heerlen, The Netherlands
Conclusions MV-PCI during the index of primary PCI in STEMI patients is associated with a higher mortality rate, a higher risk of bleeding complications, but lower risk of re-intervention and re-infarction and comparable rates of MACE.

Keywords STEMI $\cdot$ Multivessel diseases $\cdot$ Multivessel PCI $\cdot$ Infarct-related artery

\section{Background}

About half of the patients presenting with ST-elevation myocardial infarction (STEMI) have multivessel disease. Compared with STEMI patients with single-vessel disease, STEMI patients with multivessel disease have a worse prognosis [1-3].

The current guidelines recommend intervention in the infarct-related artery only during primary percutaneous coronary intervention (PCI) except in haemodynamically unstable patients [4]; this is mainly due to the fact that evidence supporting immediate (preventive) intervention in the non-infarct-related artery is a matter of debate.

There are controversial data regarding infarct-related artery only revascularisation (IRA-PCI) versus multivessel revascularisation (MV-PCI) in STEMI patients with multivessel disease [5-19].

Previously, other meta-analyses assessed MV-PCI versus IRA-PCI; however, in those meta-analysis, MV-PCI was defined as same stage PCI as well as staged PCI days after the primary PCI. Furthermore, the results of the most recent trials were not included [20-23].

We performed a meta-analysis comparing outcome in MV-PCI versus IRA-PCI during the index of primary PCI in STEMI patients with multivessel disease. 


\section{Methods}

Literature review

The literature search was performed from Cochrane Library, EMBASE and MEDLINE, from January 2014 to December 2014. The terms "ST-elevation myocardial infarction", "coronary angioplasty", "percutaneous coronary intervention", "multi-vessel", "non-culprit", "culprit coronary revascularisation", "complete revascularisation", "myocardial infarction" and their variations were used as keywords. The search was limited to records in humans and English language articles.

\section{Study selection}

Two reviewers independently screened all citations for eligibility. Both randomised controlled trials (RCTs) and cohort studies comparing multivessel versus culprit-only PCI in patients with STEMI and multivessel coronary artery disease treated with primary PCI were included. Studies enrolling patients with other than STEMI or comparing alternative revascularisation strategies were excluded. Fulltext citations and abstracts were selected and independently screened for eligibility in the meta-analysis. The unpublished Complete Versus culprit-Lesion only PRimary PCI Trial (CVLPRIT) was also included because of its importance for this meta-analysis [20]. Quality of abstracted studies was assessed using the Cochrane Collaboration's tool for assessing risk of bias [24].

Information on study design, inclusion and exclusion criteria, number of patients and clinical outcome was extracted by two investigators. Disagreements were resolved by consensus. Finally, all co-authors had full access to all study data and take responsibility for the integrity of the data and the accuracy of the data analysis.

\section{Definitions}

MV-PCI was defined as PCI of the infarct-related artery (IRA) and non-IRA performed during the index primary PCI procedure for STEMI. IRA-PCI is defined as the PCI of the IRA only during the index primary PCI procedure. Major adverse cardiac event (MACE) was defined as the composite of death, re-infarction and revascularisation. Bleeding included both minor and major bleeding.

\section{Endpoints/data abstraction}

The primary clinical endpoint was all-cause mortality. Secondary endpoints were re-infarction, revascularisation, bleeding and MACE.
Statistical analysis

Continuous data were expressed as mean \pm standard deviation and dichotomous data as absolute values and percentages. Mantel-Haenszel model was used to construct random effects summary odds ratios (ORs) and risk differences. All analyses were performed using Review Manager (RevMan, Version 5.0, The Nordic Cochrane Centre, The Cochrane Collaboration 2008) and SAS 9.3, (SAS Institute, Cary, $\mathrm{NC)}$. $p$-Value $<0.05$ was considered statistically significant.

\section{Results}

The search yielded 15 studies [5-19]: 5 RCTs and 10 cohort studies. The characteristics of the included studies are shown in Table 1. A total of 35,975 patients comprised the study population including 1134 (3.2\%) patients from RCTs. MV-PCI was performed in 5109 (12.2\%) patients, and 30,939 (85.8\%) patients underwent IRA-PCI.

\section{Patient characteristics}

Table 2 shows the baseline characteristics of the study population. The vast majority of the studies excluded patients with cardiogenic shock and in two trials cardiogenic shock was not reported.

\section{Clinical outcomes}

The primary endpoint, all-cause mortality, was significantly higher in the MV-PCI ( $8.5 \%)$ compared with the IRA-PCI (5.4\%) group (OR 1.57, 95\% CI 1.40-1.76, $p<0.001$ ) (Fig. 1). However, analysis limited to the five RCTs only showed no significant difference in mortality rate between MV-PCI and IRA-PCI (OR 0.74, 95\% CI 0.43-1.26, $p=0.27$ ).

\section{Secondary endpoints}

Rates of re-infarction (OR $0.54,95 \%$ CI $0.34-0.88$, $p=0.01$ ) and revascularisation (OR $0.67,95 \%$ CI 0.48 $0.93, p=0.002$ ) were lower in the MV-PCI group. This was found for both randomised and cohort trials (Fig. 2a and b).

Bleeding complications (major and minor) occurred more often in the MV-PCI group: 6.2 versus $5.1 \%$, (OR $1.24,95 \%$ CI $1.08-1.42, p=0.002$ ) and this was mainly found in the cohort studies (Fig. 3).

MACE was comparable between the two groups: 19 versus $19.5 \%$ (OR $0.94,95 \%$ CI $0.74-1.19, p=0.59$ ). In the RCT trials, MACE was significantly lower in patients undergoing MV-PCI compared with the IRA-PCI group (Fig. 4). 
Table 1 Study characteristics

\begin{tabular}{|c|c|c|c|c|c|c|}
\hline Study & Design & Subjects & Inclusion criteria & Exclusion criteria & Primary endpoint & $\begin{array}{l}\text { Mean length } \\
\text { follow-up }\end{array}$ \\
\hline Cavender & Cohort study & 28,936 & $\begin{array}{l}\text { STEMI with CAD of }>1 \text { major } \\
\text { artery }\end{array}$ & $\begin{array}{l}\text { LM, staged PCI (multiple PCIs } \\
\text { before hospital discharge), } \\
\text { thrombolytic }\end{array}$ & $\begin{array}{l}\text { In-hospital } \\
\text { mortality }\end{array}$ & In-hospital \\
\hline Corpus & Cohort study & 532 & $\begin{array}{l}\text { STEMI with }>70 \% \text { stenosis of } \geq 2 \\
\text { arteries }\end{array}$ & $\begin{array}{l}\text { PCI of graft or after angio- } \\
\text { plasty, LM, planned staged } \\
\text { revascularisation }\end{array}$ & MACE & 12 months \\
\hline Di Mario & Randomised & 69 & $\begin{array}{l}\text { STEMI with MVD and } 1-3 \\
\text { lesions in non-culprit artery tech- } \\
\text { nically amenable to revascularisa- } \\
\text { tion by stent }\end{array}$ & $\begin{array}{l}\text { Lesion in vein and arterial grafts, } \\
\text { prior angioplasty, thrombolytic, } \\
\text { cardiogenic shock, LM }\end{array}$ & $\begin{array}{l}\text { Repeat } \\
\text { revascularisation }\end{array}$ & 12 months \\
\hline Dziewierz & Cohort study & 777 & $\begin{array}{l}\text { STEMI with MVD 2-3 lesions in } \\
\text { non-culprit artery }\end{array}$ & CABG & $\begin{array}{l}\text { All-cause } \\
\text { mortality }\end{array}$ & 12 months \\
\hline Hannan & Cohort study & 1006 & STEMI with MVD & $\begin{array}{l}\text { LM disease, prior thrombolysis, } \\
\text { prior CABG, cardiogenic shock, } \\
\text { missing EF }\end{array}$ & $\begin{array}{l}\text { All-cause } \\
\text { mortality }\end{array}$ & 42 months \\
\hline Khattab & Cohort study & 73 & $\begin{array}{l}\text { STEMI with }>70 \% \text { stenosis of } \\
\geq 2 \text { coronary arteries or major } \\
\text { branches }\end{array}$ & $\begin{array}{l}\text { Non-IRA diameter }<2.5 \mathrm{~mm} \text {, } \\
\text { LM disease, previous MI }\end{array}$ & MACE & 12 months \\
\hline Kornowski & Cohort study & 668 & STEMI with MVD & TIMI flow $<3$ in non-IRA & MACE & 12 months \\
\hline Ochala & Randomised & 92 & $\begin{array}{l}\text { STEMI with }>70 \% \text { stenosis of } \geq 2 \\
\text { coronary arteries, successful PCI } \\
\text { of IRA }\end{array}$ & $\begin{array}{l}\text { Cardiogenic shock, LM disease, } \\
\text { pervious CABG, renal insuffi- } \\
\text { ciency, severe valvular disease }\end{array}$ & $\begin{array}{l}\text { Improvement in } \\
\text { LVEF }\end{array}$ & 6 months \\
\hline Politi & Randomised & 214 & $\begin{array}{l}\text { STEMI with }>70 \% \text { stenosis of } \\
\geq 2 \text { coronary arteries or major } \\
\text { branches }\end{array}$ & $\begin{array}{l}\text { Cardiogenic shock, } \mathrm{LM}>50 \% \text {, } \\
\text { pervious CABG, severe valvular } \\
\text { heart disease or unsuccessful } \\
\text { procedure }\end{array}$ & MACE & 30 months \\
\hline Qarawani & Cohort study & 120 & $\begin{array}{l}\text { STEMI with }>70 \% \text { multivessel } \\
\text { narrowing }\end{array}$ & Cardiogenic shock, LM disease & Clinical outcome & 12 months \\
\hline Roe & Cohort study & 129 & $\begin{array}{l}\text { STEMI with } \geq 50 \% \text { stenosis of } \geq 1 \\
\text { non-culprit artery in addition to } \\
\text { culprit IRA }\end{array}$ & $\begin{array}{l}\text { PCI of branch vessels of IRA, } \\
\text { LM disease }\end{array}$ & $\begin{array}{l}\text { MACE (death, } \\
\text { re-MI, and } \\
\text { revascularisation) }\end{array}$ & 6 months \\
\hline Toma & Cohort study & 2201 & $\begin{array}{l}\text { STEMI with }>70 \% \text { stenosis of }>1 \\
\text { major epicardial artery and/or a } \\
\text { non-IRA requiring intervention }\end{array}$ & $\begin{array}{l}\text { PCI on LM, second intervention } \\
\text { in the culprit artery }\end{array}$ & $\begin{array}{l}\text { MACE (death, } \\
\text { CHF, shock) }\end{array}$ & 3 months \\
\hline Varani & Cohort study & 399 & $\begin{array}{l}\text { STEMI with }>70 \% \text { stenosis of } \\
\geq 2 \text { epicardial arteries or major } \\
\text { branches }\end{array}$ & $\begin{array}{l}\text { Occlusion after prior angioplas- } \\
\text { ty, cardiogenic shock, pulmonary } \\
\text { oedema }\end{array}$ & $\begin{array}{l}\text { Death and repeat } \\
\text { revascularisation }\end{array}$ & 1 month \\
\hline Wald & Randomised & 465 & $\begin{array}{l}\text { STEMI with } \geq 50 \% \text { stenosis of } \geq 1 \\
\text { non-IRA in addition to IRA }\end{array}$ & $\begin{array}{l}\text { Cardiogenic shock, } \mathrm{LM}>50 \% \text {, } \\
\text { pervious CABG }\end{array}$ & MACE & 23 months \\
\hline Gershlick & Randomised & 294 & $\begin{array}{l}\text { STEMI with }>70 \% \text { stenosis of } \\
\geq 2 \text { epicardial arteries or major } \\
\text { branches }(>2 \mathrm{~mm})\end{array}$ & $\begin{array}{l}\text { Cardiogenic shock, previous MI, } \\
\text { pervious CABG, chronic kidney } \\
\text { disease, CTO }\end{array}$ & MACE & 12 months \\
\hline
\end{tabular}

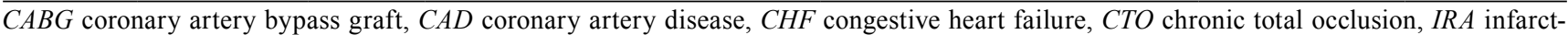
related artery, $L M$ left main artery, $L V E F$ left ventricular ejection fraction, $M A C E$ major adverse cardiac events, $M I$ myocardial infarction, $M V D$ multivessel disease, PCI percutaneous coronary intervention, STEMI ST-elevation myocardial infarction, TIMI thrombolysis in myocardial infarction

\section{Discussion}

In this large scale meta-analysis, we found that PCI of the IRA and non-IRA performed during the index primary PCI procedure for STEMI, compared with IRA-only PCI, is associated with a higher mortality rate and more bleeding complications, but less re-infarction and revascularisation. Rates of MACE were comparable between the two groups. However, there was a clear difference in outcome between the randomised trials and cohort studies. In the cohort stud- ies, mortality and bleeding complications were significantly higher in the MV-PCI group; however, these were not significantly different in the randomised trials between the MV-PCI group versus IRA-PCI group (Figs. 1 and 4).

Approximately $40-65 \%$ of patients with STEMI have multivessel disease with increased risk of morbidity and mortality compared with single-vessel disease [1-3]. The underlying mechanism for this adverse prognosis may be plaque instability, impaired myocardial perfusion and contractility, arrhythmia and death. 
Table 2 Baseline characteristics

\begin{tabular}{|c|c|c|c|c|c|c|c|c|c|c|}
\hline \multirow[t]{2}{*}{ Study } & \multicolumn{2}{|l|}{ Age } & \multicolumn{2}{|l|}{ Male $(\%)$} & \multicolumn{2}{|c|}{ Diabetes $(\%)$} & \multicolumn{2}{|c|}{ Anterior MI (\%) } & \multicolumn{2}{|c|}{ Cardiogenic shock $(\%)$} \\
\hline & MV-PCI & IRA-PCI & MV-PCI & IRA-PCI & MV-PCI & IRA-PCI & MV-PCI & IRA-PCI & MV-PCI & IRA-PCI \\
\hline Cavender & 60 & 62 & 71.5 & 72.1 & 24.7 & 23.4 & NR & NR & 13.8 & 10.3 \\
\hline Corpus & 64 & 63 & 70 & 70 & 19 & 17 & NR & NR & 3.3 & 3.4 \\
\hline Di Mario & 64 & 65 & 88.2 & 84.6 & 11.5 & 41.5 & 51.9 & 58.8 & Excluded & Excluded \\
\hline Dziewier & 68 & 68 & 72.2 & 72.2 & NR & NR & NR & NR & $\begin{array}{l}\text { Not } \\
\text { reported }\end{array}$ & $\begin{array}{l}\text { Not } \\
\text { reported }\end{array}$ \\
\hline Hannan & NR & NR & 77.5 & 75.5 & 23.7 & 21.4 & NR & NR & Excluded & Excluded \\
\hline Khattab & 69 & 65 & 75 & 78 & 7 & 16 & 57 & 54 & 3.6 & 4.4 \\
\hline Kornowski & 62 & 63.5 & 80.9 & 79.6 & 15.3 & 18.1 & 40.6 & 35.1 & $\begin{array}{l}\text { Not } \\
\text { reported }\end{array}$ & $\begin{array}{l}\text { Not } \\
\text { reported }\end{array}$ \\
\hline Ochala & 65 & 67 & 72.9 & 75 & 31 & 34 & 45.8 & 45.4 & Excluded & Excluded \\
\hline Politi & 65 & 65 & 76.9 & 77.8 & 14 & 21 & 48 & 43 & Excluded & Excluded \\
\hline Qarawani & 66 & 67 & 62 & 61 & 13 & 16 & 51 & 52 & Excluded & Excluded \\
\hline Roe & 64 & 63 & 77.2 & 65.8 & 37 & 29 & 46 & 41 & 28 & 28 \\
\hline Toma & 64 & 64 & 74 & 73 & 12 & 20 & 56 & 48 & 3 & 3 \\
\hline Varani & 69 & 67 & 68.7 & 67 & NR & NR & 49 & 34 & Excluded & Excluded \\
\hline Wald & 62 & 62 & 76 & 81 & 35 & 48 & 29 & 39 & Excluded & Excluded \\
\hline Gershlick & 65 & 65 & 85 & 77 & 12.9 & 14.3 & 36 & 35.6 & Excluded & Excluded \\
\hline
\end{tabular}

$I R A-P C I$ infarct-related artery only revascularisation, $M I$ myocardial infarction, $M V-P C I$ multivessel revascularisation, $N R$ not reported

The potential advantages of MV-PCI during the index primary PCI may prevent recurrent ischaemia and infarction by decreasing total ischaemia and improvement in myocardial function $[25,26]$. Plaque instability may not be limited to the IRA but may involve other territories in the coronary vasculature. Moreover, complete revascularisation has been associated with improved long-term clinical outcome in patients with stable coronary artery disease.
Finally, patients and clinicians may be more comfortable with complete revascularisation rather than medical therapy for angiographically significant residual coronary stenosis, especially if they are associated with a large territory of myocardial jeopardy [27-30].

However, multivessel PCI also has disadvantages. In the acute phase of STEMI, intervention of a non-culprit lesion may result in unnecessary haemodynamic compromise dur-
Fig. 1 Forest plot of all-cause mortality

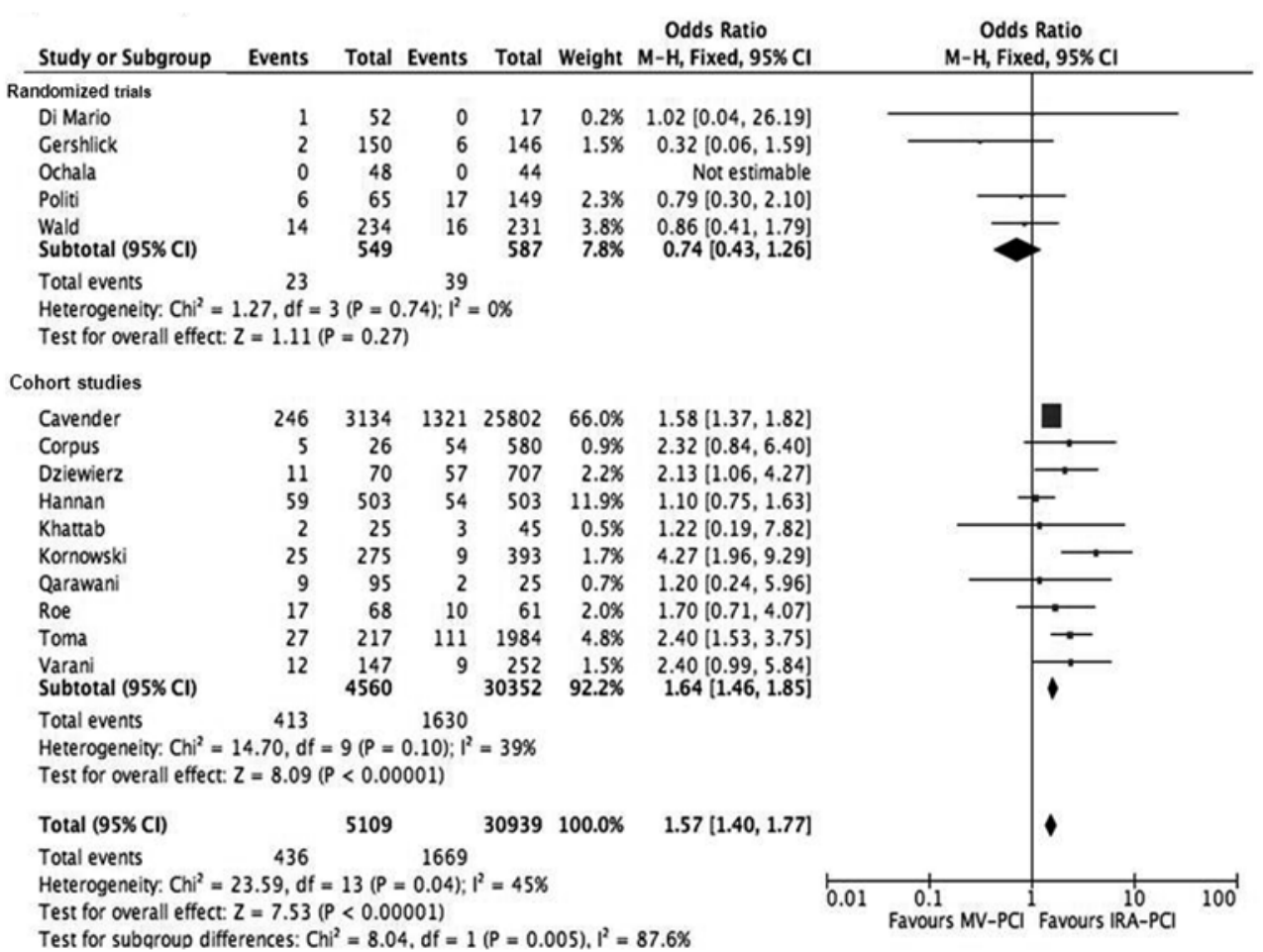


Fig. 2 a Forest plot of re-infarction. b Forest plot of re-percutaneous coronary intervention

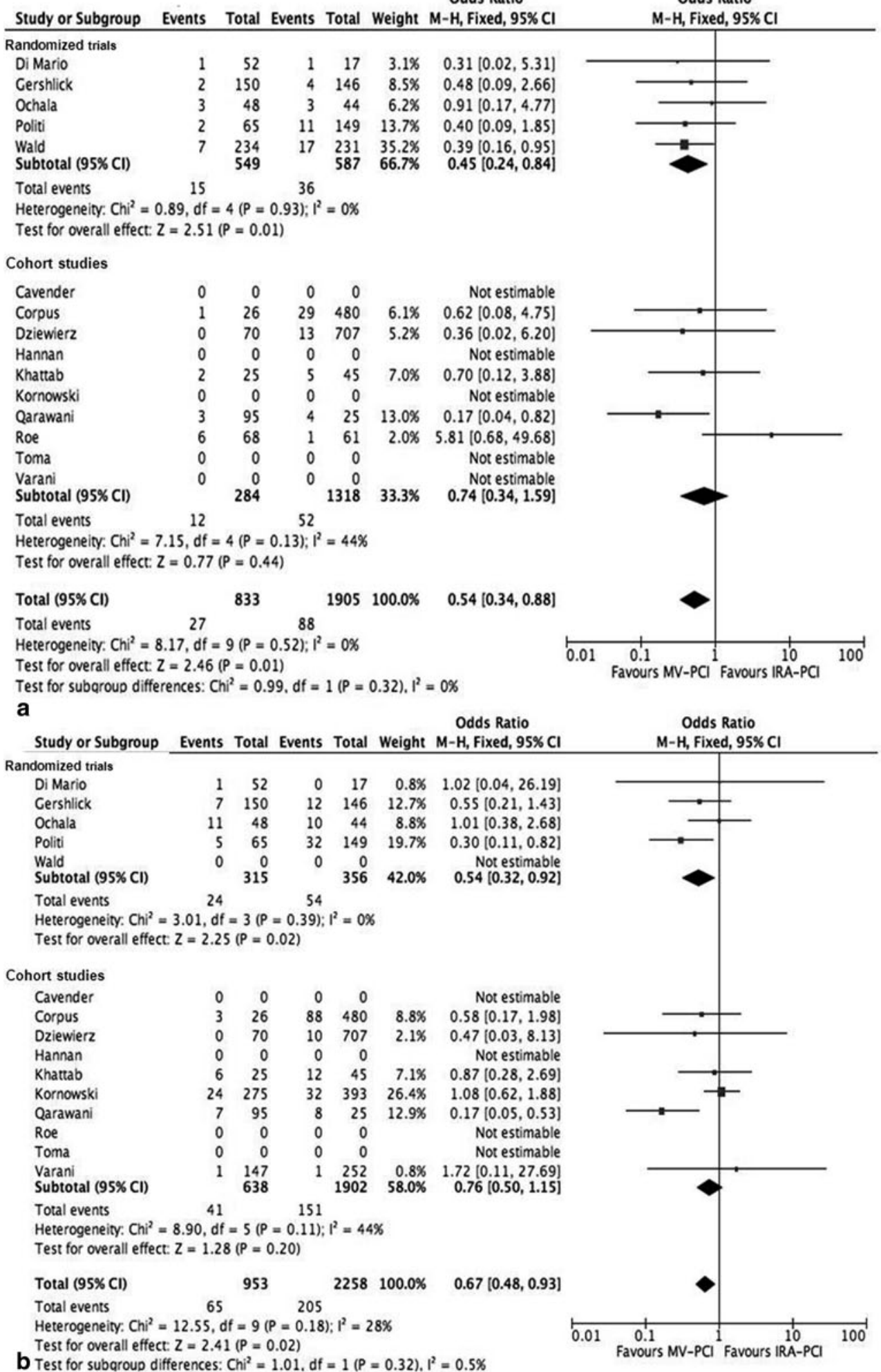

ing PCI with balloon inflations or vessel-related complications (dissection, no-reflow) at a time when the patient has regional myocardial compromise. Given the extended duration of the intervention, increased contrast load and additional adverse peri-procedural outcomes may occur. Another important concern is poor assessment of lesion severity in non-culprit artery [22]. Hanratty et al. [30] demonstrated that $21 \%$ of the non-culprit lesions are overestimated at time of AMI, and this may affect unnecessary revascularisation and inappropriate decision making. The severity of the 
Fig. 3 Forest plot of bleeding (major and minor)

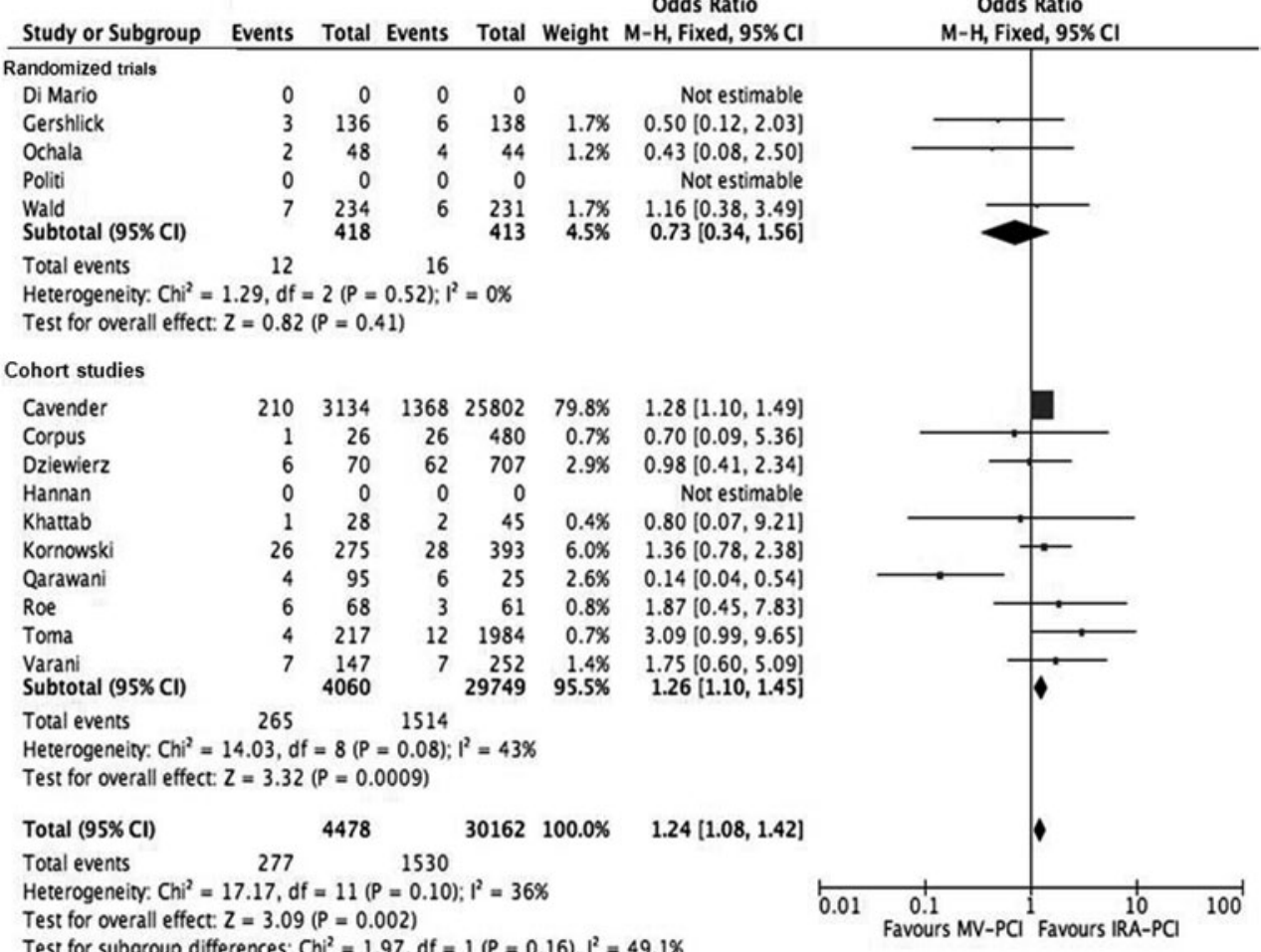

Fig. 4 Forest plot of major adverse cardiac events (death, re-infarction and re-percutaneous coronary intervention)

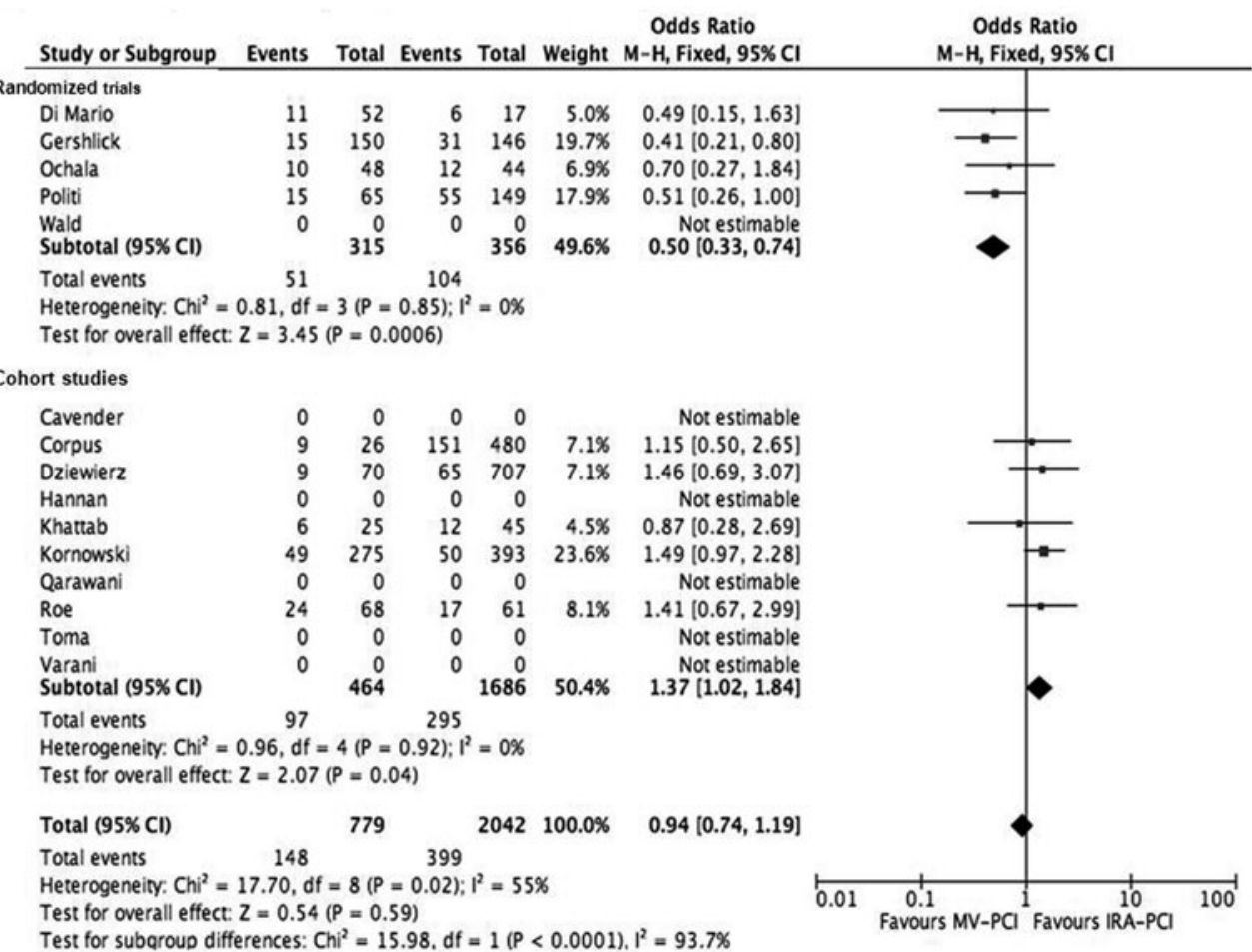

non-culprit artery was judged visually and PCI of the nonIRA was not ischaemia guided in any of the studies included in this meta-analysis.

There is only one randomised study in which revascularisations on the non-IRA was guided by fractional flow reserve (FFR). FFR of the non-IRA was performed 7.5 days after primary PCI, and they found functional stenosis severity of non-culprit lesions is frequently overestimated and invasive strategy for non-culprit lesions did not lead to an increase in ejection fraction or a reduction in MACE [31]. 
Prior meta-analyses in this area have reported varying results due to differences in study design, comparison of different groups and different analytical methods [20-23]. Vlaar et al. [20] found that the strategy of staged PCI resulted in lower short- and long-term mortality compared with MV-PCI or IRA-PCI. Bangalore et al. [21] found that MV-PCI compared with IRA-PCI resulted in similar longterm mortality but a lower long-term rate of MACE. A recent meta-analysis showed that MV-PCI compared with IRA-PCI resulted in worse outcomes in cohort studies, but not in the randomised clinical trials [22]. This is in line with our findings.

Furthermore, Bainey et al. [23] found that staged multivessel PCI was superior to multivessel PCI during the index procedure.

The difference in outcome between the IRA-only and MV-PCI group may not only be due to revascularisation, differences in baseline may also play an important role. Patients in the MV-PCI group have a higher baseline risk evidenced by a higher proportion of anterior myocardial infarction and more cardiogenic shock.

Based on the current evidence, we think that in the acute phase of STEMI, revascularisation should be limited to the IRA only, except in patients with haemodynamic instability, as recommended by the current guidelines [4]. Staged and ischaemia-driven revascularisation of non-culprit lesions may be the treatment strategy for STEMI patients with multivessel disease. Further studies are needed to confirm this. The current ongoing COMPLETE and COMPARE ACUTE trials are studying these issues.

\section{Limitations}

This meta-analysis was not performed on individual patient data. Caution should be exercised in the interpretation of the results, given the potential clinical heterogeneity among trials, due to varying patient populations and potential treatment bias. No information was available with regard to extent of coronary disease, use of drug-eluting stents, duration of dual antiplatelet therapy and access site. The short follow-up period of some studies is another important limitation. Furthermore, only a minority of the patients (14.2\%) undergo MV-PCI during the index procedure, so it is hard to draw definitive conclusions based on this meta-analysis.

In addition, no information was available regarding referral method, ambulance versus referring via non-PCI centres, factors that may affect total ischaemic time [32].

Finally, although the STEMI and non-STEMI are not uniquely related to different pathophysiological mechanisms [33], our results cannot be applied to non-STEMI patients with multivessel disease.

\section{Conclusion}

Multivessel PCI during the index of primary PCI in STEMI patients is associated with a higher mortality and more bleeding, but a lower risk of re-intervention and re-infarction. Additional large-scale randomised trials are needed to guide the therapy and the timing for these patient subsets.

Funding None.

\section{Conflict of interest None.}

Open Access This article is distributed under the terms of the Creative Commons Attribution License which permits any use, distribution, and reproduction in any medium, provided the original author(s) and source are credited.

\section{References}

1. van der Schaaf RJ, Timmer JR, Ottervanger JP, et al. Long-term impact of multivessel disease on cause-specific mortality after ST elevation myocardial infarction treated with reperfusion therapy. Heart. 2006;92:1760-3.

2. Muller DW, Topol EJ, Ellis SG, et al. Multivessel coronary artery disease: a key predictor of short-term prognosis after reperfusion therapy for acute myocardial infarction. Thrombolysis and Angioplasty in Myocardial Infarction (TAMI) Study Group. Am Heart J. 1991;121:1042-9.

3. Sorajja P, Gersh BJ, Cox DA, et al. Impact of multivessel disease on reperfusion success and clinical outcomes in patients undergoing primary percutaneous coronary intervention for acute myocardial infarction. Eur Heart J. 2007;28:1709-16.

4. The Task Force on the management of ST-segment elevation acute myocardial infarction of the European Society of Cardiology (ESC). ESC Guidelines for the management of acute myocardial infarction in patients presenting with ST-segment elevation. Eur Heart J. 2012;33:2569-619.

5. Cavender MA, Milford-Beland S, Roe MT, et al. Prevalence, predictors, and in-hospital outcomes of non-infarct artery intervention during primary percutaneous coronary intervention for ST-segment elevation myocardial infarction (from the National Cardiovascular Data Registry). Am J Cardiol. 2009;104:507-13.

6. Corpus RA, House JA, Marso SP, et al. Multivessel percutaneous coronary intervention in patients with multivessel disease and acute myocardial infarction. Am Heart J. 2004;148:493-500.

7. Di Mario C, Mara S, Flavio A, et al. Single vs multivessel treatment during primary angioplasty: results of the multicentre randomised HEpacoat for cuLPrit or multivessel stenting for Acute Myocardial Infarction (HELP AMI) Study. Int J Cardiovasc Intervent. 2004;6:128-33.

8. Dziewierz A, Siudak Z, Rakowski T, et al. Impact of multivessel coronary artery disease and noninfarct-related artery revascularization on outcome of patients with ST-elevation myocardial infarction transferred for primary percutaneous coronary intervention (from the EUROTRANSFER Registry). Am J Cardiol. 2010;106:342-7.

9. Hannan EL, Samadashvili Z, Walford G, et al. Culprit vessel percutaneous coronary intervention versus multivessel and staged percutaneous coronary intervention for ST-segment elevation myocardial infarction patients with multivessel disease. JACC Cardiovasc Interv. 2010;3:22-31. 
10. Khattab AA, Abdel-Wahab M, Rother C, et al. Multi-vessel stenting during primary percutaneous coronary intervention for acute myocardial infarction. A single-center experience. Clin Res Cardiol. 2008;97:32-8.

11. Kornowski R, Mehran R, Dangas G, et al. Prognostic impact of staged versus "one-time" multivessel percutaneous intervention in acute myocardial infarction: analysis from the HORIZONS-AMI (harmonizing outcomes with revascularization and stents in acute myocardial infarction) trial. J Am Coll Cardiol. 2011;58:704-11.

12. Ochala A, Smolka GA, Wojakowski W, et al. The function of the left ventricle after complete multivessel one-stage percutaneous coronary intervention in patients with acute myocardial infarction. J Invasive Cardiol. 2004;16:699-702.

13. Politi L, Sgura F, Rossi R, et al. A randomised trial of target-vessel versus multi-vessel revascularisation in ST-elevation myocardial infarction: major adverse cardiac events during long-term followup. Heart. 2010;96:662-7.

14. Qarawani D, Nahir M, Abboud M, et al. Culprit only versus complete coronary revascularization during primary PCI. Int J Cardiol. 2008;123:288-92.

15. Roe MT, Cura FA, Joski PS, et al. Initial experience with multivessel percutaneous coronary intervention during mechanical reperfusion for acute myocardial infarction. Am J Cardiol. 2001;88:170-3, A6

16. Toma M, Buller CE, Westerhout CM, et al. Non-culprit coronary artery percutaneous coronary intervention during acute ST-segment elevation myocardial infarction: insights from the APEXAMI trial. Eur Heart J. 2010;31:1701-7.

17. Varani E, Balducelli M, Aquilina M, et al. Single or multivessel percutaneous coronary intervention in ST-elevation myocardial infarction patients. Catheter Cardiovasc Interv. 2008;72:927-33.

18. Wald DS, Morris JK, Wald NJ, et al. PRAMI Investigators. Randomized trial of preventive angioplasty in myocardial infarction. N Engl J Med. 2013;369:1115-23.

19. The Complete Versus culprit-Lesion only PRimary PCI Trial (CVLPRIT). http://www.escardio.org/about/press/esc-congress-2014/ press-conferences/Documents/gershlick.pdf (Hotline Session, ESC 1 sep. 2014).

20. Vlaar PJ, Mahmoud KD, Holmes DR, Jr., et al. Culprit vessel only versus multivessel and staged percutaneous coronary intervention for multivessel disease in patients presenting with ST-segment elevation myocardial infarction: a pairwise and network meta-analysis. J Am Coll Cardiol. 2011;58:692-703.

21. Bangalore S, Kumar S, Poddar KL, et al. Meta-analysis of multivessel coronary artery revascularization versus culpritonly revascularization in patients with ST-segment elevation myocardial infarction and multivessel disease. Am J Cardiol. 2011;107:1300-10.
22. Bagai A, Thavendiranathan $P$, Sharieff W, Al Lawati HA, Cheema AN. Non-infarct-related artery revascularization during primary percutaneous coronary intervention for ST-segment elevation myocardial infarction: a systematic review and meta-analysis. Am Heart J. 2013;166:684-693.e1.

23. Bainey KR, Mehta SR, Lai T, Welsh RC. Complete vs culprit-only revascularization for patients with multivessel disease undergoing primary percutaneous coronary intervention for ST-segment elevation myocardial infarction: a systematic review and meta-analysis. Am Heart J. 2014;167:1-14.e2

24. Higgins JP. Cochrane handbook for systematic reviews of interventions. West Sussex: Wiley; 2008.

25. Asakura M, Ueda Y, Yamaguchi O, et al. Extensive development of vulnerable plaques as a pan-coronary process in patients with myocardial infarction: an angioscopic study. J Am Coll Cardiol. 2001;37:1284-8.

26. Goldstein JA, Demetriou D, Grines CL, et al. Multiple complex coronary plaques in patients with acute myocardial infarction. $\mathrm{N}$ Engl J Med. 2000;343:915-22.

27. Bell MR, Gersh BJ, Schaff HV, et al. Effect of completeness of revascularization on long-term outcome of patients with three-vessel disease undergoing coronary artery bypass surgery. A report from the Coronary Artery Surgery Study (CASS) Registry. Circulation. 1992;86:446-57.

28. Jones EL, Weintraub WS. The importance of completeness of revascularization during long-term follow-up after coronary artery operations. J Thorac Cardiovasc Surg. 1996;112:227-37.

29. Wu C, Dyer AM, King SB, III, et al. Impact of incomplete revascularization on long-term mortality after coronary stenting. Circ Cardiovasc Interv. 2011;4:413-21.

30. Hanratty CG, Koyama Y, Rasmussen HH, et al. Exaggeration of nonculprit stenosis severity during acute myocardial infarction: implications for immediate multivessel revascularization. J Am Coll Cardiol. 2002;40:911-6.

31. Dambrink JH, Debrauwere JP, van 't Hof AW, et al. Non-culprit lesions detected during primary PCI: treat invasively or follow the guidelines? Eurointervention. 2010;5:968-75.

32. Postma S, Dambrink JH, de Boer MJ, et al. The influence of residential distance on time to treatment in ST-elevation myocardial infarction patients. Neth Heart J. 2014;22:513-9.

33. IJkema BB, Bonnier JJ, Schoors D, Schalij MJ, Swenne CA. Role of the ECG in initial acute coronary syndrome triage: primary PCI regardless presence of ST elevation or of non-ST elevation. Neth Heart J. 2014;22:484-90. 